\title{
Producer prices and services producer prices: implementation of SIC 2007
}

Simon Woodsford

Office for National Statistics

\section{Summary}

This article provides information about producer price index (PPI) and services producer price index (SPPI) implementation of the United Kingdom Standard Industrial Classification of All Economic Activities 2007 (UK SIC 2007). Classification systems are used to record business establishments and other standard units by the type of economic activity in which they are engaged.

\section{Overview}

Since 1948 the United Kingdom Standard Industrial Classification of All Economic Activities (UK SIC) has been revised six times in 1958, 1968, 1980, 1992, 1997 and 2003 (the changes in 1997 and 2003 were not full-scale revisions). The introduction of the SIC 2007 represents the first major revision since 1992. These revisions are motivated by the need to adapt the classifications to changes in the world economy. In essence, the introduction of this latest classification change reflects the growing importance of service activities in the economy of the last 15 years and in particular the developments in information and communication technologies.

Producer prices (PPI) and service producer prices (SPPI) both implemented the change onto UK SIC 2007 in November 2010. The most significant change to PPI output prices is the reclassification of recovered secondary raw materials (recycling) and publishing out of manufacturing and into the service sector. The SIC 2007 project has included fundamental changes made to the classification of the PPI trade surveys, import price indices (IPI) and export price indices (EPI). The collection of these is now on a SIC basis, a switch from the Standard International Trade Classification (SITC) and Combined Nomenclature (CN) previously used. As a result PPI trade surveys are now compliant with Eurostat short term statistics regulation. This change of classification used will have a direct impact on the framework structure of PPI input prices, as IPI's account for a large proportion of total input price sales. For SPPI, apart from adopting recovered secondary raw materials and publishing, changes resulting in the implementation of SIC 2007 will be largely cosmetic. 


\section{Effects of reclassification on PPI output prices}

Output (or factory gate) prices measure change in the price of goods produced by UK manufacturers. These are weighted together using 2005 sales from PRODCOM (for gross sector output) and National Accounts supply/use tables (for net sector output). The series still have a reference year of $2005=100$.

For many of the SIC division level output prices the effect on index levels and growth rates due to the reclassification from SIC 2003 to SIC 2007 is minimal. This is due to the majority of component products remaining broadly, and in some cases exactly, in the same divisional classification framework. The areas of greatest change to output prices are due to:

- recovered secondary raw materials and publishing - under SIC 2007 these products are no longer classified as manufacturing activities and have been reclassified within the service sector. As a result the collection, sales and weight of all recycling and publishing items are now excluded from the PPI. These activities have been removed from the historical series published back to 1996

- repair, installation and maintenance of machinery and equipment is a new division which has been formed under SIC 2007. The size of this activity now warrants its own SIC division within the manufacturing sector. Under SIC 2003 these activities were included but only as part of each specific manufacturing industry, in particular in machinery and equipment not elsewhere classified, computers, electronic and optical equipment, and transport equipment

Figure 1 shows the comparison of net sector output index levels and Figure 2 shows the comparison of net sector output 12 month rates. Table 1 identifies the weighting structure for 'all manufacturing net sector output' on an SIC 2003 and SIC 2007 basis.

\section{Effects of reclassification on PPI trade prices (IPI and EPI)}

The largest impact on PPI trade prices will be the switch of collecting IPI and EPI on an SIC basis, from the Standard International Trade Classification (SITC) for IPI, and Combined Nomenclature $(\mathrm{CN})$ for EPI. This change means that both trade surveys are now compliant with Eurostat short term statistics regulation. It also makes the classification used in all PPI surveys consistent. IPI has also been separated into EU and Non-EU and so are now also consistent with the EPI structure.

SITC is a hierarchy classification derived by the United Nations concerned with dividing products firstly by materials used (for example all meat products are classified together irrespective of how they arrived at that point). It is more commonly known as classification by 'material composition by degree of transformation'. 


\section{Figure $1 \quad$ Output PPI index values (SIC 2003 and SIC 2007)}

Output prices $(2005=100)$

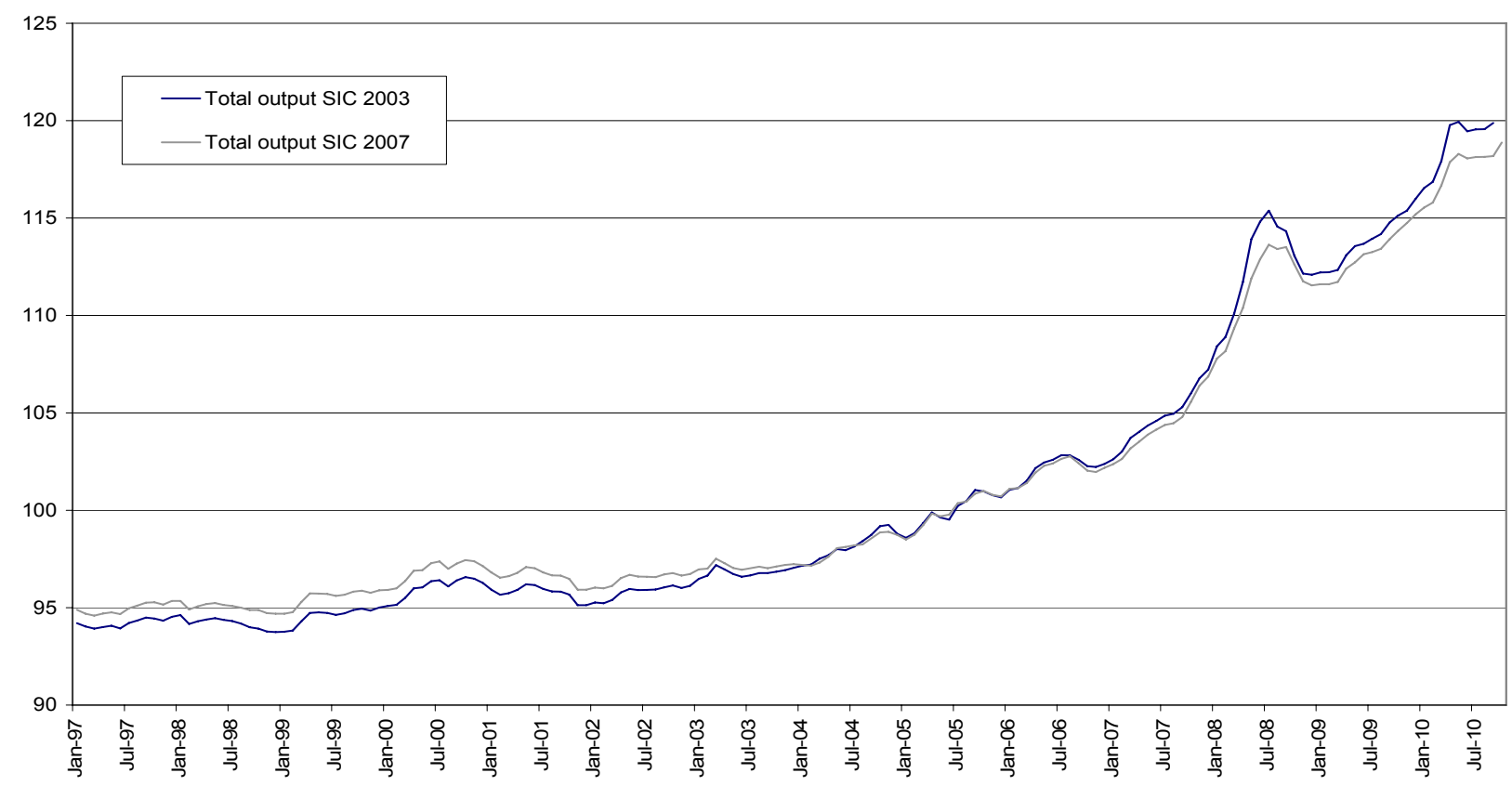

Source: Producer prices

Figure 2 Output PPI 12 month percentage changes (SIC 2003 and SIC 2007)

Per cent, month on same month 1 year ago

Difference \%

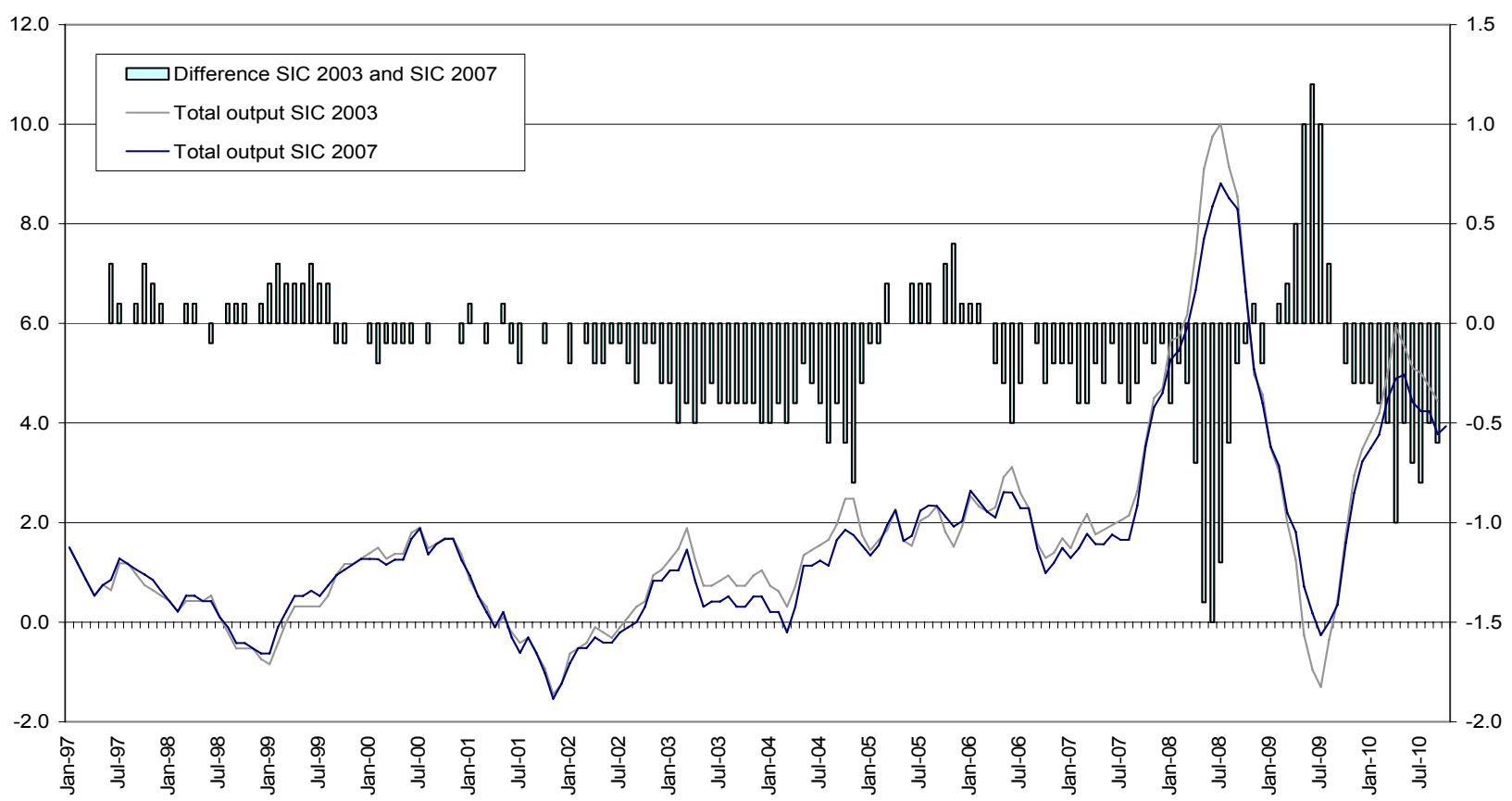

Source: Producer prices 
Table 1 All manufacturing net sector weights in SIC 2003 and SIC 2007

\begin{tabular}{|c|c|c|c|c|}
\hline SIC 03 & & SIC 07 & & Difference (\%) \\
\hline Description & Weight (\%) & Description & Weight (\%) & \\
\hline Mineral Water and Soft Drinks & 1.1 & Mineral Water and Soft Drinks & 1.2 & 0.1 \\
\hline Food Products & 14.2 & Food Products & 14.9 & 0.7 \\
\hline Alcohol Products (inc duty) & 6.1 & Alcohol Products (inc duty) & 6.4 & 0.3 \\
\hline Tobacco Products (inc duty) & 3.1 & Tobacco Products (inc duty) & 3.3 & 0.2 \\
\hline Textile Products & 3.1 & Textile Products & 3.3 & 0.2 \\
\hline Clothing Products & 6.9 & Clothing Products & 7.2 & 0.3 \\
\hline Leather Products & 1.7 & Leather Products & 1.8 & 0.1 \\
\hline Wood and Wood Products & 1.1 & Wood and Wood Products & 1.2 & 0.1 \\
\hline Pulp, Paper and Printing & 1.8 & Pulp, Paper and Printing & 1.9 & 0.1 \\
\hline Printing and Recording Services & 5.1 & Printing and Recording Services & 2.1 & -3.0 \\
\hline Petroleum Products & 8.8 & Petroleum Products & 9.2 & 0.4 \\
\hline Chemical Products & 7.7 & Chemical Products & 8.1 & 0.4 \\
\hline Rubber and Plastics & 2.8 & Rubber and Plastics & 2.9 & 0.1 \\
\hline Other Non Metallic Minerals & 2.9 & Other Non Metallic Minerals & 3.0 & 0.1 \\
\hline Metals and Metal Products & 2.4 & Metals and Metal Products & 2.9 & 0.5 \\
\hline Machinery \& Equipment n.e.c & 3.4 & Machinery \& Equipment n.e.c. & 0.6 & -2.8 \\
\hline $\begin{array}{l}\text { Computers, Electronic \& Optical } \\
\text { Products, Electrical Equipment }\end{array}$ & 8.7 & $\begin{array}{l}\text { Computers, Electronic \& Optical } \\
\text { Products, Electrical Equipment }\end{array}$ & 9.6 & 0.9 \\
\hline Transport Equipment & 11.4 & Transport Equipment & 11.1 & -0.3 \\
\hline \multirow[t]{2}{*}{ Other Manufactured Goods n.e.c. } & 7.7 & Other Manufactured Goods n.e.c. & 6.5 & -1.2 \\
\hline & & $\begin{array}{l}\text { Repair and Maintenance and installation } \\
\text { of machinery and equipment }\end{array}$ & 2.8 & 2.8 \\
\hline All Manufactured Products & 100.0 & All Manufactured Products & 100.0 & \\
\hline
\end{tabular}

Harmonised Description and Coding System (HS) is an international trade classification set up by World Customs Organisation designed for customs tariffs and trade negotiations. The CN classification is specifically designed for the EU region and is concerned with the grouping of products as they would be categorised at customs borders. The $\mathrm{CN}$ classification is consistent with the HS classification structure at the 6 digit level. $\mathrm{CN}$ is more commonly referred to as classification by 'degree of transformation by material composition'.

Within PPI specifically the use of SIC refers to who buys and produces that product, or more generally relates to where business establishments are classified by economic activity. 
An example of how this change in classification method has affected hierarchal structures are the classifications of 'meat' and 'raw hides and skins'. 'Meat' is classified in SITC division 01 for 'bovine animals', while 'raw hides and skins' are classified in SITC division 21 for 'raw hides and skins', so in separate divisions. Under the SIC 2007 framework these are both classified as products of the meat industry and so fall in the same SIC Division 10 for 'food'.

\section{Effects of Reclassification on PPI input prices}

Input prices measure the change in the price of raw materials and fuels bought by UK manufacturers for processing. These are structured using 'home produced' and 'imported' components, and are weighted together using National Accounts supply/use tables. These also still have a reference year of $2005=100$.

The areas of most significant change to the composition of the all manufacturing input structure are:

- the change in the classification system used for IPI from SITC to SIC. This change of classification method will have a direct impact on the framework structure of PPI input prices, as IPI's account for a large proportion of total input price sales

- the reclassification of input/output (I/O) groupings that form the basis of the PPI input structure onto an SIC 2007 basis have had a substantial effect on weighting structures. The impact is more evident where several I/O groups on an SIC 2003 basis have either been merged into one on a SIC 2007, or also vice-versa. For example, in SIC 2003 the component for imported motor vehicles, trailers and semi-trailers all fell in one I/O group, but on an SIC 2007 basis these are split between three I/O groups

Such changes have had more of an effect on the 'imported components' of the input structure. However the 'home produced' element of input prices have also been effected by these changes to I/O groups albeit the impact is less. This is mainly due to the fairly stable structure of influential I/O groups within the home produced components, such as food. These I/O group changes have effected the home produced component the most in places where sales for $1 / O$ groups were previously excluded on an SIC 2003 basis due to not collecting any products within that specific I/O group, and which have now been merged with other $\mathrm{I} / \mathrm{O}$ groups that products are collected. For example, sales for SIC 2003 group for 'mining of metal ores' was previously excluded from the input price structure due to not collecting any prices within the UK for these specific products. However the SIC 2007 I/O group for 'mining of metal ores has merged with the I/O group for 'other mining and quarrying products'. Therefore the sales for this new combined I/O group are used in the input price hierarchy and so will have a greater weight in the SIC 2007 structure than it did on a SIC 2003 basis.

All these changes will have an impact on the framework structure of input prices but it is impossible to separate the effects of these various changes.

Figure 3 shows the comparison of net sector output index levels and Figure 4 shows the comparison of net sector output 12 month rates. Table 2 shows the change to the weighting structure for components of all manufacturing net sector input. 
Figure 3 Input PPI index values (SIC 2003 and SIC 2007)

Input prices $(2005=100)$

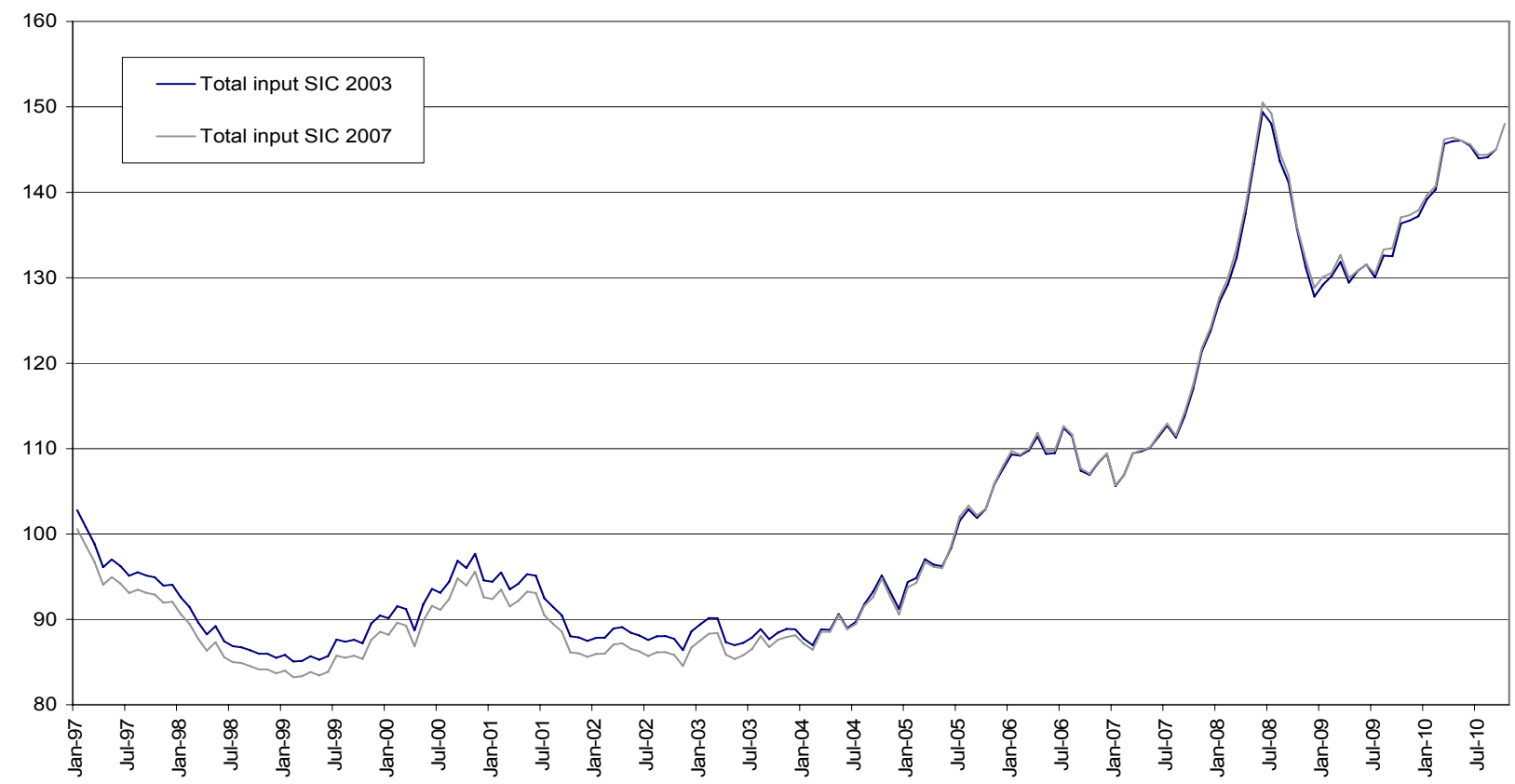

Source: Producer prices

Figure 4 Input PPI 12 month percentage changes (SIC 2003 and SIC 2007)

Per cent, month on same month 1 year ago

Difference \%

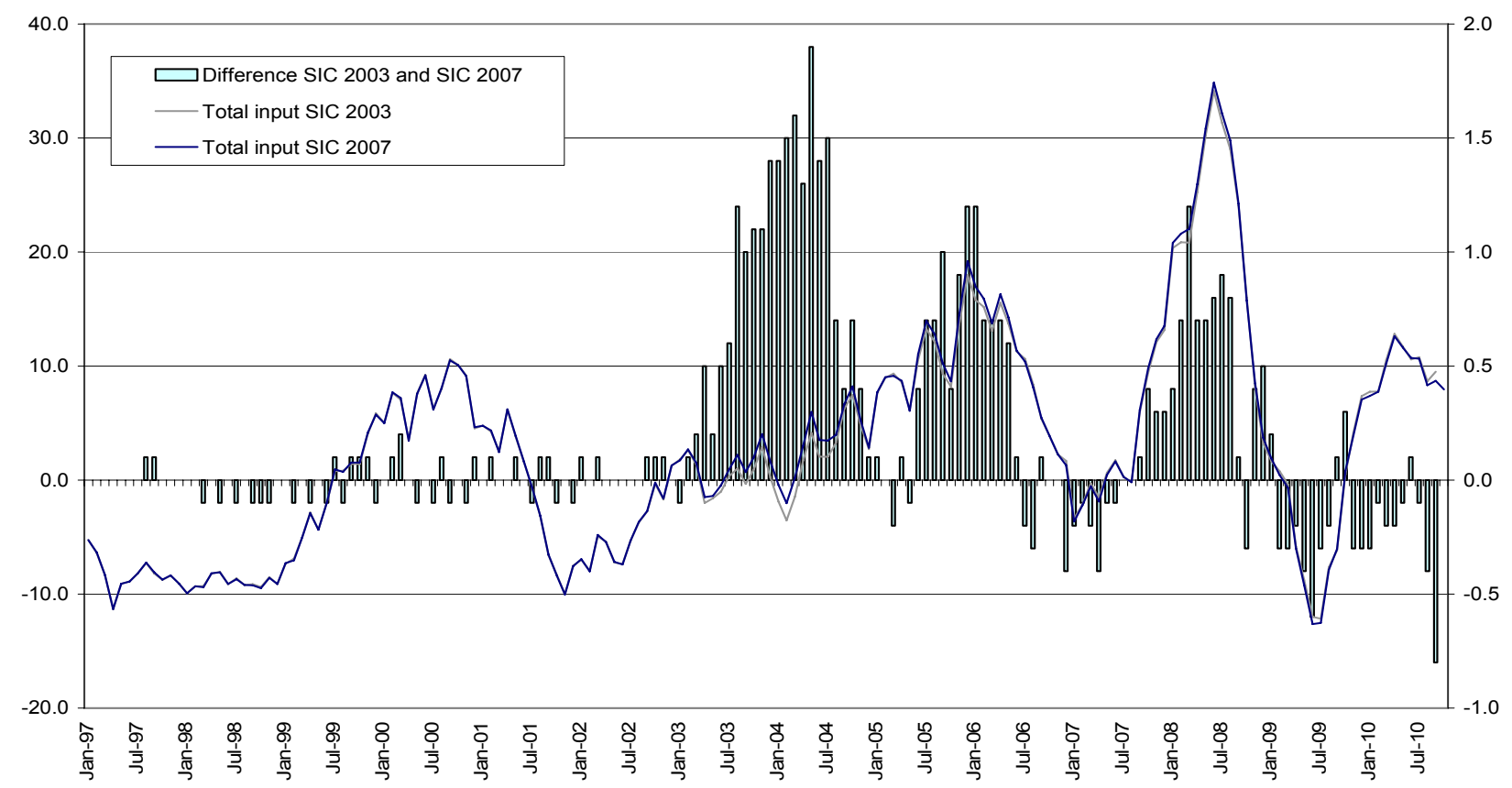

Source: Producer prices 


\section{Table 2 Changes to weights for all manufacturing net inputs, SIC 2003 and SIC 2007}

\begin{tabular}{lclcc}
\hline \multicolumn{1}{c}{ SIC 03 } & & & SIC 07 & Difference (\%) \\
\hline \multicolumn{1}{c}{ Description } & Weight (\%) & \multicolumn{1}{c}{ Description } & Weight (\%) \\
Home Produced Food & 11.1 & Home Produced Food & 10.7 & -0.4 \\
Other Home Produced Materials & 2.9 & Other Home Produced Materials & 4.9 & 2.0 \\
Crude Oil & 19.0 & Crude Oil & 19.4 & 0.4 \\
Electricity & 5.3 & Electricity & 5.5 & 0.2 \\
Gas & 3.5 & Gas & 3.6 & 0.1 \\
Imported Food & 5.5 & Imported Food & 5.5 & 0.1 \\
Imported Metals & 6.7 & Imported Metals & 7.0 & 0.3 \\
Imported Chemicals & 11.4 & Imported Chemicals & 12.1 & 0.6 \\
Imported Parts \& Equipment & 23.4 & Imported Parts \& Equipment & 19.8 & -3.6 \\
Other Imports & 11.2 & Other Imports & 11.5 & 0.3 \\
All Manufacturing & 100.0 & All Manufacturing & 100.0 &
\end{tabular}

\section{Impact of reclassification of prices' on National Accounts estimates}

National Accounts have announced that then plan to switch to SIC 2007 in September 2011. PPI (including IPI and EPI) and SPPI are widely used for deflation purposes within the National Accounts. In order to ensure that National Accounts estimates continue to be deflated using consistent SIC 2003 price deflators, Prices Division will continue to supply National Accounts with SIC 2003 PPI and SPPI deflators until September 2011. These SIC 2003 based price indices will not be routinely published on the Office for National Statistics website.

\section{Effects of reclassification on SPPI}

Generally the effects of the switch to SIC 2007 to the details of SPPI will be very minimal and largely cosmetic as the structure of SPPI is not currently closely based on a SIC 2003 basis like the PPI. At the total net and gross sector SPPI level, these indices will adopt recovered secondary raw materials and publishing activities which previously fell in the manufacturing sector. We have taken this opportunity to also include historic and late data changes.

\section{Contact}

For further information about the implementation of SIC 2007 in PPI and SPPI please contact ppi@ons.gov.uk 